\section{Mastering by the teacher of the instrumental genesis in CAS environments: necessity of intrumental orchestrations}

Dominique Guin, Luc Trouche Montpellier (France)

\begin{abstract}
In this article, we study didactic phenomena identified in integration experiments within our classes, CAS (implemented in calculators). From this study, we show the interest of an instrumental approach to understand the influence of tools on the mathematical approach and on the building of students' knowledge: through a process - instrumental genesis a calculator becomes a mathematical work tool; this process depends on the tool's constraints and potentialities, on students' knowledge, and on the class' work situations. To analyze the differentiation of instrumental genesis, we then have taken interest in students' behaviour and we propose a method enabling us to constitute a typology of extreme behaviour in environments of symbolic calculators. To take the variety of these genesis into account, the professor needs a particular organization of space and time of the study in the class. We suggest the notion of instrumental orchestration to name this organization. We demonstrate how this notion gives a better definition of the objectives, the configurations and the exploitation modes of different arrangements which aim at constituting coherent instrument systems for each student and for the class.
\end{abstract}

Kurzreferat: Umgang der LehrerInnen mit der instrumentalen Genese in CAS-Umgebungen: Notwendigkeit von instrumentalen Orchestrierungen. In diesem Beitrag werden didaktische Phänomene diskutiert, die bei der Integration von CAS (implementiert in Taschenrechnern) in den Unterricht auftreten. Basierend auf diesen Untersuchungen wird der Nutzen eines instrumentalen Zugangs für das Verständnis des Einflusses von Werkzeugen auf mathematische Zugänge und für den Aufbau von SchülerInnenwissen gezeigt: durch einen Prozess - instrumentale Genese - wird ein Taschenrechner zu einem mathematischen Werkzeug; dieser Prozess ist abhängig von den Grenzen und Potenzialen dieses Werkzeugs, vom Wissen der SchülerInnen und von den Arbeitssituationen im Unterricht. Für die Analyse von Unterschieden in der instrumentalen Genese wird dann das Verhalten von SchülerInnen untersucht und eine Methode vorgeschlagen, die es ermöglicht, eine Typologie extremer Arbeitsweisen in Umgebungen symbolischer Rechner anzugeben. Eine Berücksichtigung der unterschiedlichen instrumentalen Genesen erfordert vom Lehrer bzw. der Lehrerin eine besondere Organisation von Raum und Zeit der Arbeit im Unterricht. Es wird vorgeschlagen diese Organisation als instrumentale Orchestrierung zu bezeichnen. In der Folge wird gezeigt, wie eine solche Vorstellung eine bessere Definition der Ziele, der Strukturen und der Umsetzungsformen verschiedener Anordnungen ermöglicht, die darauf abzielen, für jede/n SchülerIn kohärente Systeme von Instrumenten zu schaffen.

ZDM-Classification: C30, C60, C70, D30, D40, I40, U70

\section{From a tool to an instrument, a complex process}

\subsection{Didactic phenomena identified during the first experimentations}

In the first research on the integration of ICT, optimistic discourses were dominant (Penglase \& Arnold 1996). Over the last fifty years, researchers' speeches have been more cautious (Lagrange \& al 2001). Research on the integration, first of all, of graphic calculators (from the 1980's) then of CAS DERIVE (carried out in France within an institutional context from 1991), last, of symbolic calculators have thus shown several didactic phenomena. Artigue (1997, p. 148) distinguishes two interrelated classes - the class of phenomena linked to processes of knowledge transposition and that of phenomena linked to students' adaptation processes -.

\subsubsection{Didactic phenomena linked to computer-based transposition processes}

Computer transposition is described by Balacheff (1994) as "this work on knowledge which allows a symbolic representation of it and the implementation of this representation by a computer system". Artigue finds two phenomena related to this transposition:

- the pseudo-transparency phenomenon, linked to the gap between what is written by the student and what is displayed on the screen;

- the phenomenon of double reference linked to the double interpretation of tasks, depending on whether one works in a paper/pencil environment or in a CAS environment.

In the same way, Drijvers (in this issue) identifies the non-transparency of the computer algebra tool as a global obstacle for students while working in a computer algebra environment.

\subsubsection{Didactic phenomena linked to students adaptation processes}

Perceptive adaptation phenomena are linked to the calculator's display potentialities. We have thus shown (Guin \& Trouche 1999) that the answer to the question: "Does the $\mathrm{f}$ function defined by $\mathrm{f}(\mathrm{x})=\ln \mathrm{x}+\sin \mathrm{x}$ accept as a limit $+\infty$ in $+\infty$ ?" strongly depends on the environment (whereas elementary theorems allow to answer yes to the question).

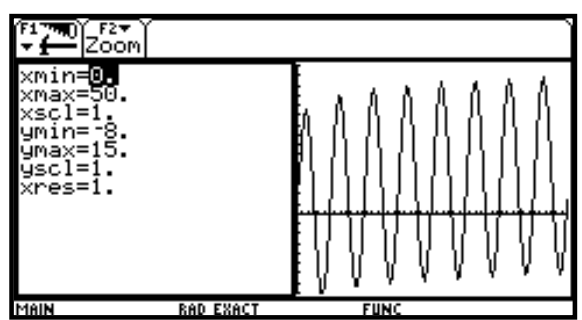

Figure 1: A representation of the function $x \mapsto \ln \mathrm{x}+10 \sin \mathrm{x}$.

If students have a graphic calculator, $25 \%$ of them answer no, due to the oscillation of the observed graphic representation (Figure 1); within a group of same level students deprived of a graphic calculator, only $5 \%$ of wrong answers are collected. The very economy of the 
students' work is thus altered by the multiplicity of easily available commands. Artigue (1997, p. 162) highlights a kind of fishing behaviour: "One does trials with no concern for their organization or their check up, hoping that within a reasonable time something interesting will show up".

In an experimental class equipped with symbolic calculators, we have also noted (Trouche, in Guin \& Trouche 2002) several phenomena:

- an automatic transport phenomenon, based on the idea that the complexity of the calculator allows the student to directly solve the given problem provided that one can feed all the problem's data into the machine:

- a localized relentless determination phenomenon linked to the difficulty to change the semiotic registers (Duval 1996) and thus to change the applications on a symbolic calculator. It consists in reproducing the same type of technique, in the same application, but in performing a series of successive adjustments.

This necessary taking into account of the potentialities and constraints of new tools, the more precise study of processes through which students take them over and use them, and more generally, the attention paid to the mediations necessary to every learning process, have spurred research into new theoretical approaches (Artigue 2001) enabling to understand better the role played by material and symbolic instruments in mathematics activity.

\subsection{A new approach to understand and describe new phenomena}

Recent work in cognitive ergonomy gives theoretical tools to understand CAS integration processes better. Verillon and Rabardel (1995) stress the difference between the artifact - a material object - and the instrument as a psychological construct: "the instrument does not exist in itself, it becomes an instrument when the subject has been able to appropriate it for himself and has integrated it with his activity". This construction, or instrumental genesis, is a complex process, linked to the artifact's characteristics (its potentialities and its constraints) and to the subject's activity, his/her knowledge, and former working habits.

\subsubsection{Analyzis of symbolic calculators' constraints and potentialities}

The computer transposition and the choices of designers produce in a symbolic calculator constraints to be analyzed so as to be able to anticipate or understand instrumental genesis. We have distinguished (Guin \& Trouche 1999) three types of constraints:

- internal constraints intrinsically linked to the hardware;

- command constraints linked to the existence and to the form (that is to say the syntax) of the various commands;

- last, organization constraints linked to the organization of the keyboard and of the screen.

It is, of course, possible to discuss the nature of a given constraint in one of the three defined types (examples can be found in Guin \& Trouche 1999, p. 203-205). But it seems interesting to us to distinguish the elementary level of a gesture, linked to a command key, and the more complex level of a technique, i.e. the organization of action in order to realize a given task (a technique appears as a combination of several gestures $\S 1.3$ ). The interest of a typology of constraints is not to define, in a very strict manner, totally self-enclosed categories but rather to make it easier for the professor or for the researcher, to undertake the a-priori analysis of different ways, which the artifact provides to perform a series of tasks. The user is not totally "free" to use as s/he thinks best a given tool. At the same time, by relieving users of a part of their work and by encouraging the exploration of representations in different registers (Yerushalmy 1997), the tool opens new possibilities for learning and conceptualization. To know these possibilities is not simple: (Bottino \& Furinghetti 1996) note that even experienced teachers only use a small part of the available technology. However, it is difficult to separate potentialities from constraints: both are intimately mixed, every facility given to the user being at the same time an incentive to undertake a type of action rather than another one. "These tools wrap up some of the mathematical ontology of the environment and form part of the web of ideas and actions embedded in it" (Noss \& Hoyles 1996).

\subsubsection{The two components of instrumental genesis}

Instrumental genesis has two components:

- an instrumentalization component, related to the artifact;

- an instrumentation component related to the organization of the subject's behaviour.

Instrumentalization can go through different stages: a stage of discovery and selection of the relevant keys, a stage of personalization (one fits the tool to one's hand) and a stage of transformation of the artifact, sometimes in directions unplanned by the designer: modification of the task bar, creation of keyboard shortcuts, storage of game programs, automatic execution of some tasks (calculator builders' sites or personal sites of particularly active users thus offer programs of function study, of resolution of some classes of equations etc.). The instrumentalization is also a process of differentiation of the artifacts themselves.

Instrumentation is relative to the emergence and evolution of schemes of a subject for the execution of a given task. Vergnaud (1996) refers to schemes to define the invariant organization of the behaviour in a given class of situations (for example, the scheme of resolution of a second degree equation). This organization lies on operative invariants: they are the implicit knowledge contained in schemes, which can be concepts-in-acts or theorems-in-acts, that is to say concepts or propositions implicitly held as true.

At the outcome of its genesis, an instrument is constituted, as for its material part, by a part of the artifact - modified from its initial state, by the instrumentalization processes - as for its psychological part by the schemes built by the subject, relative to the execution of a type of tasks. That is to say that a symbolic calculator will provide a given student subject-matter for several instruments, related to several types of tasks. The articulation of this set of instruments, i.e. the construction of a system of instruments is a complex task, which we will examine in section 3. 
Instrumental genesis has individual aspects and social aspects. The "balance" between these two aspects depends on:

- material factors (it is obvious that the intimacy of calculator screens favors more individual work than a computer screen which can accept work by a small group of students);

- tool availability (students can only use calculators in the mathematics class, sometimes they are lent to them for the whole year, sometimes they belong to them);

- the taking into account of this tool by the teacher within the class and the integration arrangement which the latter one builds.

\subsubsection{To describe the instrumented activity}

Human activity (and students in particular) can be described as techniques, that is to say, sets of gestures built by the subject to accomplish a given task (Lagrange 2000). A gesture, elementary grain of the activity, can have several functions (Trouche 2000, p. 257). To understand the function of a gesture requires it not to be considered in isolation but within the activity performed by the student to achieve a given task.

One will talk about instrumented technique when the set of gestures (or part of this set) are instrumented gestures, that is to say gestures articulated to an instrument in the sense which we have defined. A technique can be described, and therefore can be taught, which does not solve the issue of its learning: one can note, in every class, the discrepancy between techniques taught by the teacher and techniques practiced by students.

One can also describe this activity with the notion of instrumented action scheme, which implies to take interest in the operative invariants. The scheme being what connects a gesture to a thought, it is only its emerged part that is accessible to the observer. A scheme is thus an observer's construct made from the different traces of the subject's activity.

\section{Differentiation of individual instrumental geneses}

\subsection{Proposition of a typology}

Finer analyses of students' work in symbolic calculator environments (Drijvers 2000) show a great variety of working method. To grasp the variety of this behaviour requires taking into account different elements on a lasting term. We have (Trouche 2000, p. 251) considered:

- information sources used, which can be the previously built references, resort to paper/pencil, the calculator, or to the neighbourhood (in particular, during practicals);

- time of tool utilization (both the global time of the calculator's use and time spent performing each instrumented gesture);

- relationship of students to mathematics in particular the proof method (proof can proceed from analogy, demonstration, accumulation of corroborating clues);

- their relationship to knowledge: metaknowledge that is to say knowledge which students have built on their own knowledge (Pitrat 1990, Robert \& Robinet 1996).

We have attributed to the person's control of her/his own activity a central role, within a chart of essential knowledge, which is required in mathematics activity, in particular, in an environment of symbolic calculators. It distinguishes two types of metaknowledge:

- first-level metaknowledge which allows to seek information (investigation) into several sources: built - both material and psychological - references, paper/pencil, the calculator, other students - in particular within groupwork - which allows to store this information or to express it;

- second-level metaknowledge which allows to process this information (semantic interpretation, inference, coordination-comparison of information originating from one or several sources, from one or several calculator's applications).

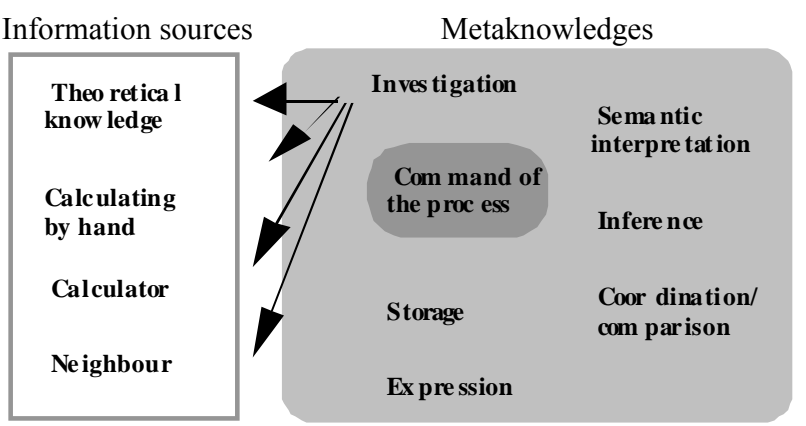

Figure 2: Information sources and metaknowledge

This chart itself does not allow to completely describe a subject's behaviour:

- each metaknowledge should be more clearly defined; for example investigation does not have the same character if it is merely applied to the calculator or to the textbook, or to the neighbourhood or if it unfolds itself in all directions; the storage of new knowledge can be achieved alongside former knowledge or can accompany cognitive reorganization (we know from (Dorfler 1993) and (Ruthven \& Chaplin 1997) that experiences with calculators do not easily lead to such a cognitive reorganization);

- one should give a more precise description of the order in which the different types of metaknowledge are made use of, the respective time attributed to each of them. This precise description could be given when one has to describe the action of a given subject aiming at executing a given task in a given environment. The above chart could then provide us with an analysis grid of this action.

Considering these different clues, we have noticed, observing students' work over a whole year and from the analysis of their written productions and questionnaires which have been regularly handed out to them, five types of extreme behaviour:

- a theoretical work method, characterized by the use of mathematical references as a systematic resource. Reasoning is essentially based on analogy and overexcessive interpretation of facts with average verifying procedures of machine results;

- a rational work method, characterized by a reduced use of calculator, mainly working within traditional (paper/pencil) environment. The specificity of this 
behaviour is a strong student's command process with an important role played by inferences in reasoning;

- a random work method, characterized by similar student difficulties whether in the calculator environment or in the traditional paper/pencil environment. The tasks are carried out by means of cut and paste strategies from previously memorized solutions or hastily generalized observations. Therefore, the rather weak students' command process is revealed by trial and error procedures with very limited references to understanding tools and without verifying strategies of machine results;

- a mechanical work method, characterized by information sources more or less restricted to the calculator investigations and simple manipulations. However, reasoning is based on the accumulation of consistent machine results. Student's command process remains rather weak, with an avoidance of mathematical references;

- a resourceful work method, characterized by an exploration of all available information sources (calculator, but also paper/pencil work and some theoretical references). Reasoning is based on the comparison and the confrontation of this information with an average degree of student's command process. This is revealed by an investigation of a wide range of imaginative solution strategies: sometimes observations prevail, other times theoretical results predominate.

Time devoted to each gesture is also an important element when discriminating the various types of behaviour. For example, time spent on each instrumented gesture is extremely brief with mechanical work method and rational work method. This time is much longer for theoretical work method.

\subsection{Illustration of this typology}

We will illustrate this typology here from a task given to a 12th grade class whose students possessed each a symbolic calculator TI-92. The problem was to determine the $n$th derivative of the $f$ function defined on $R$ by $f(x)=$ $\mathrm{e}^{\mathrm{x}}\left(\mathrm{x}^{2}+\mathrm{x}+1\right)$. The CAS does not give any general answer (Figure 3); however $\mathrm{d}(\mathrm{f}(\mathrm{x}), \mathrm{x}, \mathrm{n})$ syntax communicated to students gives an expression of the nth derivative for particular values, positive integers of $n$.

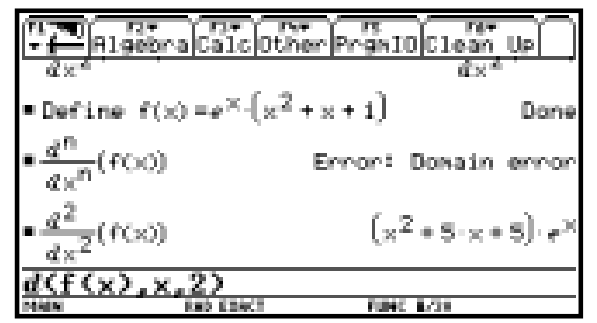

Figure 3

The determination of nth derivatives of the $\mathrm{f}$ function for several values of $n$ (Figure 4) can allow to conjecture (which requires good organization of the research and some observation qualities) a general expression for the nth derivative.

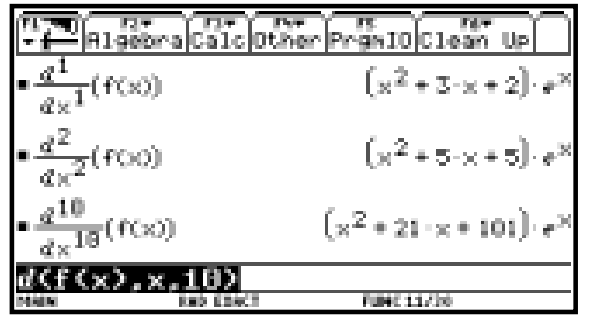

Figure 4

This work will incite students to follow different research procedures. Numerous techniques are implemented, based on paper/pencil or on the calculator. One can distinguish some working styles illustrating the typology proposed in 2.1:

- theoretical work method: the student begins by determining the first two derivatives by hand. He notes: "One will always find a function in the form of a product of the exponential function and of degree 2 polynomial"; then: "the coefficient of $x^{2}$ will always be 1 ; for the coefficient of $\mathrm{x}$, one adds 2 each time, one will therefore find 1 and 2 times something: for the coefficient of $\mathrm{x}$, it is the sum of the two preceding coefficients". As for this last coefficient, the student has a first idea: "this reminds me of Pascal's triangle, in which each combination is the sum of two combinations of inferior rank". Then: "this comes down to adding successive even numbers, it is a well-known exercise, one must find a square number". The calculator is then used to verify this general result; - rational work method: the student does a few successive paper/pencil derivatives, then a few derivatives with the calculator. All the results are noted on paper. A conjecture crops up rather fast: the nth derivative seems to be in the $e^{x}\left[x^{2}+(2 n+1) x+n^{2}+1\right]$ form. The proof is then given thanks to recurrence reasoning performed on paper/pencil;

- random work method: for the sake of increased safety, derivatives are calculated with paper/pencil and with calculator. Calculations are long because the basic techniques have been badly mastered. Thus the function is entered into the calculator in the form $e^{x^{2}+x+1}$, which makes conciliation difficult with the result obtained without the calculator. Given the impossibility to find coherence between the various results, it is the results given by the calculator for the first derivatives, which are given, without the possibility to imagine a general formula;

- mechanical work method: the function is rapidly entered into the calculator's function index. Very numerous successive derivatives are searched for until the idea of a general result comes up. The proof is given by the accumulation of results, which tally (the student tells the teacher: "The formula works fine for any value of $\mathrm{n}$. The proof: give me any value you want, you will see that it will work!"). The whole work is achieved on the machine, with no paper trace;

- resourceful work method: calculations are paper/pencil performed and performed with the calculator at the same time. To find a general formula, numerous techniques are used: factorization and expression 
development, calculation of the nth derivative for small values and great values for $\mathrm{n}$. The general formula is conjectured. The proof first rests on the fact that the formula is verified by all calculations (paper/pencil and with the calculator), but also on more general observations ("Every time, we add 2, it is normal that the coefficient of $x$ be $2 n+1$ ").

This typology has also been put to the test in other situations (Guin \& Trouche 1999). It allows to constitute geography of the class, which presents three-fold interest:

- it gives indicators to mark out, at a given moment, a student in his/her relationship with the five working styles brought to the fore. Besides, these five poles appearing a similar form in other works: Hershkowitz \& Kieran (2001) distinguish for example, two types of behaviour, linked to different coordination methods of representations in graphic calculator environment: "A mechanistic-algorithmic way (where students combine representatives in non-thinking, rote ways) and a meaningful way". The former one is close to do-ityourself behaviour. The latter one looks like the theoretical behaviour, which we have previously described;

- it gives indicators to mark out evolutions and thus to locate instrumental genesis in their moves. We have shown, for example, (Trouche 1997) significative evolutions of mechanical work method toward resourceful work method;

- it helps the teacher to play on the complementarities of the various work methods: we have shown (Trouche 1997) the interest of the association rational/ resourceful work method for practicals.

However, these evolutions significantly depend on work situations and arrangements set up by the teacher, which we are now going to study.

\section{Instrumental orchestrations}

\subsection{Didactic exploitation system and orchestration}

Paragraph 2 has shown variability, depending on students, of instrumentation processes implemented in a class ${ }^{1}$. Up to now, we have considered these geneses in their individual environments. But the instrumentation schemes also have a social dimension ${ }^{2}$, whose importance is pinpointed by Rabardel and Samurçay (2001):

“(...) They are elaborated and shared in communities of practice and may give rise to an appropriation by subjects, or even results from explicit training processes."

These "explicit training processes" partake of the responsibility of the school institution. There is thus the necessity of taking into account the building of instrumental geneses to integrate instruments within a class. This, of course, does not suppress the individual part of

\footnotetext{
${ }^{1}$ In this paragraph, the word class represents the elementary school structure unit. Propositions given rest on experimentations peformed within (10th to 12th grade) high school forms.

2 What is true for the instrument use is also true for mathematics practice. Brousseau (1998, p. 40) writes: "(...) doing mathematics is for the child, first of all, a social activity and not only an individual one."
}

these processes, but allows to reinforce the social part within them and therefore also to limit behaviourial dissipation. This taking into account first concerns the teacher in the class. Schneider (2000) clearly shows, for example, the complexity of his/her role and the far-reaching changes induced by CAS environments. Monaghan (2001) shows, for example, that in this type of environment, time devoted by the teacher to the mathematical aspects of situations can be reduced at the expenses of the technical aspects of software utilization. These changes can however be different, significantly depending on professors' teaching styles (Kendal \& Stacey 2001 \& in this issue). But the school institution includes the didactic engineer, the program designer, etc., a whole professional chain which Chevallard (1992) says it is indispensable to constitute what he names the didactic exploitation system: he uses this computer language metaphor to give prominence to the essential level which achieves coordination between didactic hardware - diverse artifacts, instructions for use, technical documents,etc. - and didactic software teaching sequences -. It is the level of didactic exploitation, which must thus guarantee the integration and the viability of computer tools used in the class. This didactic exploitation system rests on situations adapted to environments.

Dreyfus (1993) stresses the importance of the choice and the way activities are promoted by the teacher for making an effective learning tool. This way activities are promoted is linked to a specific organization of the class.

We will call instrumental orchestration a plan of action, partaking in a didactic exploitation system which an institution (the school institution, in this case) organizes with the view of guiding students' instrumented action. Instrumented orchestration is defined by four components:

- a set of individuals;

- a set of objectives (related to the achievement of a type of task or the arrangement of a work-environment);

- a didactic configuration (that is to say a general structure of the plan of action);

- a set of exploitation of this configuration;

One will distinguish main objectives, founding the necessity of the orchestration from secondary objectives linked to the chosen exploitation modes. The configuration and its exploitation modes produce traces of activity (that is to say results of the activity which can be observed by other persons than the subject involved in this activity).

Instrumental orchestrations can act at several levels:

- at the level of an artifact;

- at the level of an instrument or a set of instruments;

- at the level of the relationship of a subject with an instrument or a set of instruments.

These three levels correspond to different artifact levels, which Wartofsky (1983) distinguishes thus:

- "primary artifacts, corresponding to the concept of the tool as it is ordinarily utilized;

- second level artifacts, which correspond both to representations and action modes utilizing first level artifacts;

- third level artifacts, notably for trained persons, corresponding to the social and cognitive development by simulation situations and reflective methods of activity self-analysis, both individual and collective." 


\subsection{An example of second level instrumental orchestration}

The school utilization of individual tools, calculators fitted with a small screen, poses the problem of the socialization of students' actions and productions. This socialization requires particular arrangements. Since the beginning of the $1990 \mathrm{~s}$, there has been on every type of calculator, a particular artifact - a view-screen - which allows to project the calculator's small screen onto a big screen which the entire class can see. (Trouche, in Guin $\&$ Trouche 2002) presents an instrumental orchestration which exploits this arrangement and whose main objective is the socialization - to a certain extent - of students' instrumental genesis.

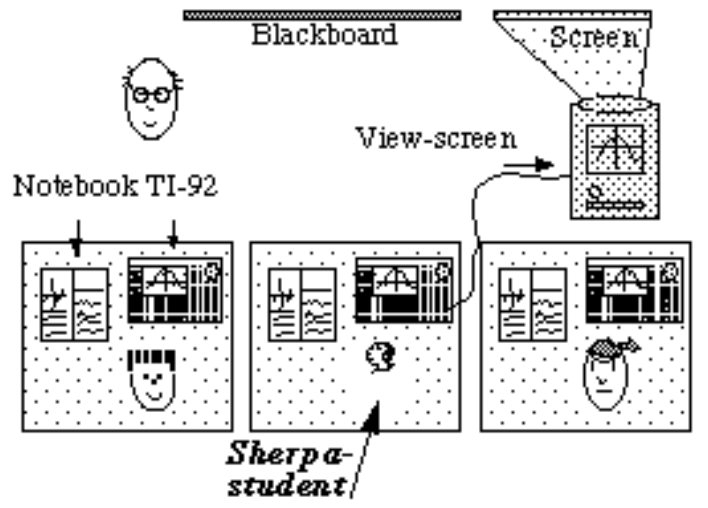

Figure 5: The sherpa-student, part of an instrumental orchestration

The configuration of this orchestration (Figure 5) rests on the devolution of a particular role to one student of the class: this student, called the sherpa-student ${ }^{3}$, pilots the overhead-projected calculator. She/he will thus be used, for both class and teacher, as reference, a guide, an auxiliary and a mediator. This orchestration favors collective management of a part of the instrumentation and instrumentalization processes: what a student does with her/his calculator, - traces of her/his activity - is seen by all, this allows to compare different instrumented techniques and give information to the teacher on the instrumented actions schemes being built by the sherpa-student.

It also presents other advantages:

- the teacher is responsible for guiding, through the student's calculator, all the class calculators (the teacher does not perform the instrumented gesture but check the conditions in which it is performed by the sherpastudent). The teacher thus fulfills the functions of an orchestra conductor rather than a one-man band ${ }^{4}$.

\footnotetext{
${ }^{3}$ On the one hand, the word sherpa refers to the person who guides and who carries the load during expeditions in the Hymalaya, and on the other hand, to diplomats who prepare international conferences.

4 This advantage is not a minor one. We have shown that teachers, in complex technological environments are strongly prone to play the conductor's role, single-handedly performing all mathematical and technical tasks linked to the resolution of problems in the class; the view-screen is then used to project the teacher's screen.
}

- for his/her teaching, the professor can combine paperpencil results obtained on the board, and results obtained by the sherpa-student's calculator on the class screen. This facilitates, to students themselves, the combination of "paper/pencil" work and their calculator work on their own desks.

Several exploitation modes of this structure can be considered. The teacher can first organize work phases of different kinds:

- sometimes calculators are shut off (and so is the overhead projector): it is then a matter of paper/pencil environment work;

- sometimes calculators are on as well as the overhead projector and work is strictly guided by the sherpastudent under the supervision of the teacher (students are supposed to have the exact same thing on their calculator-screens than on the class' big screen). Instrumentation and instrumentalization processes are then strongly constrained.

- sometimes calculators are on as well as the overhead projector and work is free over a given time. Instrumentation and instrumentalization processes are then relatively constrained (by the type of activities and by referring to the sherpa-student's calculator which remains visible on the big screen).

- sometimes calculators are on and the projector is off. Instrumentation and instrumentalization processes are then only weakly constrained.

Other variables must also be defined: will the same student play the role of the sherpa during the whole hour or, depending on announced results, should such and such student's calculator be connected to the projector table? Must the sherpa-student sit in the first row or must she/he stay at her/his usual place? Do all students play this role in turn or must only some of them be privileged?

Depending on the didactic choices made, secondary objectives of this orchestration can crop up:

- to favor debates within the class and the explicitation of procedures: the existence of another reference different from the teacher's allows the development of new relationships between the class students and the teacher, between this student and the teacher - about a result, a conjecture, a gesture or a technique -;

- to give the teacher means to reintegrate remedial or weak students into the class. The sherpa-student function actually gives remedial students another status and forces the teacher to tune his/her teaching procedures onto the work of the student who is supposed to follow her/his guidelines, follow-up work of this student on the big work-screen allows very fast feed-back actions from both teacher and class.

This instrumental orchestration partakes in the coordination of all the class instruments and favors the articulation, for each individual, of different work instruments within her/his mathematics work.

Two other examples of instrumental orchestrations can be found in (Trouche, in Guin \& Trouche 2002). The first one (first level of instrumental orchestration) is relative to the conception of an artifact devoted to the study of limits of functions. Its main objective is to favour for students the transition from a cinematic point of view to an approximate point of view. The second one (third level of 
instrumental orchestration) is a self-analysis device, the observation-mirror, which aims to give rise for students to a reflective method on their own instrumented activity by providing them observable traces of itself.

Common elements are to be found in all the orchestrations: interaction between the different subjects, explicitation of processes, publication of traces of activities (the sherpa-student screen, written research reports, timed reports of activity). They all help to reinforce the social dimension of instrumented action schemes $(\S 1.2 .3)$, that is to say, to collectively take care of a part of the instrumental genesis.

Instrumental orchestrations constrain instruments in a two-fold manner:

- they constrain the instrumented action schemes during the time of the orchestration itself;

- they constrain instrumental genesis and thus have effects, which reach out to the orchestration itself. An instrumental orchestration gives birth to new instrument systems.

The necessity of orchestrations clearly manifests itself in the learning of mathematics sciences seen as "a web of interconnected concepts and representations which must be mastered to achieve proficiency in calculation and comprehension of structures" (Noss \& Hoyles 1996). The constitution of instrument systems is also linked to the introduction of tools within the mathematics practice. Rabardel (2000) thus evokes the necessity of didactic management of these instrument systems:

"The introduction of a new artifact must, at the didactic level, be equally managed in its impact on previously built instrument systems. This issue appears particularly crucial to us in the present context of technological abundance. Which artifacts must we propose to learners and how to guide them through instrumental geneses and along the evolution and balancing of their instrument systems? For which learning activities and which building structures of mathematical knowledge?"

The conception of instrumented orchestrations seems to give us answer elements to the first question. It allows to assist the building of instrument systems by a subject.

\section{Conclusion}

Several didactic phenomena have been pinpointed during experiments of CAS integration into classes: phenomena linked to computer-based transposition and phenomena linked to students' phenomena of adaptation to tools. Understanding these phenomena requires to distinguish the technical tool given to the subject and the instrument, which is built by the subject.

This building process, - instrumental genesis - is complex; on the one hand, it is linked to the artifact's characteristics on which we have distinguished several types of constraints. On the other hand, it closely depends on the subject, thanks to the emergence and evolution of his/her schemes.

An instrument is thus defined by a part of the artifact and by schemes, which the subject builds to accomplish a type of tasks. The same tool can thus give birth to several instruments. This diversity manifests itself through the dispersion of performances in CAS environments. We have thus noticed five extreme working styles, which can be described in terms of instrumented techniques.

To control this dispersion requires the school institution to take the building construct of instrumental geneses into account. Instrumental orchestrations, integral parts of a didactic exploitation system are plans of actions, allowing to guide students' instrumented action. These obviously require some didactic engineering - arranged sequences of carefully thought-out situations aiming at reaching mathematics-learning objectives (Artigue 2000) - to be forehand set up: drawing-out the metaphor, we could say that to build an orchestration, one must have a musical score.

\section{References}

Artigue, M. (1997): Le logiciel DERIVE comme révélateur de phénomènes didactiques liés à l'utilisation d'environnements informatiques pour l'apprentissage. - In : Educational Studies in Mathematics 33(2), p. 133-169.

Artigue, M. (2000): Didactic engineering and the complexity of learning processes in classroom situations. - In: C. Bergsten, G. Dahland, B. Grevholm (eds), Proceedings of the MADIF2 Conference, Gothenburg, janvier 2000, p. 5-20, Swedish Society for Research in Mathematics Education.

Artigue, M. (2001): Learning Mathematics in a CAS Environment: The genesis of a reflection about instrumentation and the dialectics between technical and conceptual work, CAME 2001, Freudenthal Institut, Utrecht, http://ltsn.mathstore.ac.uk/came/events/freudenthal/theme1.ht $\mathrm{ml}$

Balacheff, N. (1994): Didactique et intelligence artificielle. In: Recherches en Didactique des Mathématiques 14(1/2). Grenoble: La Pensée Sauvage Editions. p. 9-42.

Bottino, R.; Furinghetti, F. (1996): The emerging of teachers' conceptions of new subjects inserted into mathematics programs: the case of informatics. - In: Educational Studies in Mathematics 30, p. 109-134.

Brousseau, G. (1998): Théorie des situations didactiques. Grenoble: La pensée Sauvage.

Chevallard, Y. (1992): Intégration et viabilité des outils informatiques. - In : Cornu B. (coord. par), L'ordinateur pour enseigner les mathématiques. Paris: PUF.

Dorfler, W. (1993): Computer Use and View of the Mind. - In: Keitel C.; Ruthven (eds), Learning From Computers: Mathematics Education and Technology, vol. 121, Nato Serie F, p. 159-186, Springer Verlag.

Dreyfus, T. (1993): Didactic design of computer-based learning environnements. - In: Keitel C.; Ruthven K. (eds), Learning from Computers: Mathematics Education and Technology, vol 121, Nato Serie F, p. 101-130, Springer-Verlag

Drijvers, P. (2000): Students Encountering Obstacles Using a CAS. - In: International Journal of Computers for Mathematical Learning 5(3), p. 189-209.

Drijvers, P. (2002): Learning mathematics in a computer algebra environment: obstacles are opportunities. - In this issue.

Duval, R. (1996): Quel cognitif retenir en didactique? - In : Recherches en Didactique des Mathématiques 16(3), p. 349-382.

Guin, D.; Trouche, L. (1999): The complex process of converting tools into mathematical instruments: the case of calculators. - In: International Journal of Computers for Mathematical Learning 3, p. 195-227.

Guin, D.; Trouche L. (eds.) (2002): Calculatrices symboliques, faire d'un outil un instrument du travail mathématique, un problème didactique. Grenoble: La Pensée Sauvage Editions.

Hershkowitz, R.; Kieran, C. (2001): Algorithmic and meaningful ways of joining together representatives within 
same mathematical activity: an experience with graphing calculators. In: Van den Heuvel - Panhuizen, M. (Ed), Proceedings of the 25th Conference of the International Group for the Psychology of Mathematics Education vol 1, p. 95-107. Utrecht: Freudenthal Institute.

Kendal, M.; Stacey, K. (2001): The Impact of teacher privileging for technopole differentiation with technology. In: International Journal of Computer for Mathematical Learning 6(2), p. 1-23.

Kendal, M.; Stacey, K. (2002): Teachers in transition: Moving towards CAS-supported classrooms. - In this issue.

Lagrange, J.-B. (2000): L'Intégration d'Instruments Informatiques dans l'Enseignement: une Approche par les Techniques. - In: Educational Studies in Mathematics 43(1), p. 1-30.

Lagrange, J.-B.; Artigue, M.; Laborde, C.; Trouche, L. (2001): A meta study on IC technologies in education; towards a multidimensional framework to tackle their integration. In:: Van den Heuvel - Panhuizen, M. (Ed): Proceedings of the 25th Conference of the International Group for the Psychology of Mathematics Education vol 1, p. 111-122. Utrecht: Freudenthal Institute.

Monaghan, J. (2001): Teachers' classroom interactions in Ictbased mathematics lessons. - In: Van den Heuvel Panhuizen, M. (Ed): Proceedings of the 25th Conference of the International Group for the Psychology of Mathematics Education vol 1, p. 383 - 390. Utrecht: Freudenthal Institute.

Noss, R.; Hoyles, C. (1996): Windows on Mathematical Meanings, p. 153-166. Dordrecht: Kluwer Academic Publishers.

Penglase, M.; Arnold, S. (1996): The Graphics Calculators in Mathematics Education: a Critical Review of Recent Research. - In: Mathematics Education Research Journal, vol 8, p. 58-90.

Pitrat, J. (1990): Métaconnaissance, futur de l'intelligence artificielle. Paris: Hermès.

Rabardel, P. (2000): Eléments pour une approche instrumentale en didactique des mathématiques, Actes de l'école d'été de didactique des mathématiques, p. 202-213, Caen : IUFM.

Rabardel, P.; Samurçay, R. (2001): From Artifact to InstrumentMediated Learning, New Challenges to Research on Learning. International symposium organized by the Center for Activity Theory and Developmental Work Research, University of Helsinki.

Robert, A.; Robinet, J. (1996): Pour une prise en compte du méta en didactique des mathématiques. - In: Recherches en Didactique des Mathématiques 16(2), p. 145-176.

Ruthven, K.; Chaplin, D. (1997): The calculator as a Cognitive Tool: Upper-primery pupils tackling a realistic number problem. - In: International Journal of Computers for Mathematical Learning 2, p. 93-124.

Schneider, E. (2000): Teacher experiences with the use of a CAS in a mathematics classroom. - In: The International Journal for Computer Algebra in Mathematics Education 7(2), p. 119-141.

Trouche, L. (1997): A propos de l'enseignement des limites de fonctions dans un "environnement calculatrice", étude des rapports entre processus de conceptualisation et processus d'instrumentation. PhD. Montpellier: Université Montpellier II.

Trouche, L. (2000): La parabole du gaucher et de la casserole à bec verseur: étude des processus d'apprentissage dans un environnement de calculatrices symboliques. - In : Educational Studies in Mathematics 41(2), p. 239-264.

Vergnaud, G. (1996): $\mathrm{Au}$ fond de l'apprentissage, la conceptualisation. - In : Noirfalise R., Perrin M.-J. (eds.) ,Actes de l'Ecole d'Eté de Didactique des Mathématiques, p. 174-185. Clermont-Ferrand: IREM, Université ClermontFerrand II.
Verillon, P.; Rabardel P. (1995): Cognition and artifacts: A contribution to the study of thought in relation to instrument activity. - In: European Journal of Psychology in Education 9(3): p. 77-101.

Wartofsky, M. (1983): From genetic epistemology to historical epistemology: Kant, Marx and Piaget. - In: Liben, L.S. (Ed.), Piaget and the fondations of knowledges, Hillsdale, N.J., Lawrence Erlbaum.

Yerushalmy, M. (1997): Reaching the unreachable: Technology and the semantics of asymptotes. - In: International Journal of Computers for Mathematical Learning 2, p. 1-25.

\section{Authors}

Guin, Dominique, Prof. Dr., ERES \& LIRMM, Universität Montpellier, cc 040, Place Eugène Bataillon, 34095 Montpellier cedex 5, France.

E-mail: guin@math.univ-montp2.fr

Trouche, Luc, Dr., ERES \& LIRMM, Universität Montpellier, cc 040, Place Eugène Bataillon, 34095 Montpellier cedex 5, France.

E-mail: trouche@math.univ-montp2.fr 